\title{
The Use of an Automatic Answering Service in Research Libraries
}

\begin{abstract}
An answering device will help fill the gap in professional service during evening and weekend hours. The inexpensive system eliminates the drawbacks of having nonprofessional personnel answer inquiries phoned in to the library.
\end{abstract}

A Ll Libraries that SERVE a research clientele share one problem. Research people (students, faculty, and others) do not observe regular business hours. Consequently, university, college, and special libraries stay open for long hours every day of the week. However, because of financial shortages and the difficulty of getting librarians to work odd hours, the library often finds it possible to offer experienced, professional services only during conventional work hours, Monday through Friday. In such cases the library is generally staffed the rest of the time by student assistants or other part-time help. Research libraries perform a desirable service by making the collection and the study facilities available during such an extensive period, but there is also a way of extending professional personnel services at a very low cost during odd hours. It is by the use of an automatic phone answering and recording machine.

The University of Michigan Law library has been successfully using such a system for about two and a half years. Its cost is modest; less than $\$ 25.00$ per month for rental of the Bell Telephone

Mr. Lewis is Assistant Law Librarian, University of California at Davis.
Automatic Answering Service machine, including the phone line, plus an initial $\$ 15.00$ installation charge. Similar machines can also be purchased outright for about $\$ 200.00$. Such devices, of course, "answer the phone" with a recorded message, then record the caller's question for later playback.

How does this machine extend library service? For one thing, it can be "on" twenty-four hours a day, whether the library is open or not. For another, it is a better system for answering many types of phoned-in questions than that of allowing the student assistant on duty to attempt to answer the question or to tell the caller to call back in the morning when the "regular librarians" are in. Many inquiries are not answered by students due to lack of knowledge or, worse yet, are answered only partially or incorrectly. The answering service can accept inquiries on such matters as reference questions, location of materials, library holdings, requests to deliver books (paging service), and such miscellaneous items as future hours of the library, information regarding personnel on the staff and faculty, why the flags are flying at half-mast, and other "information desk" type questions.

The obvious drawback to this system 
is that the question is not answered immediately. However, the question is recorded immediately and accurately. This means that the researcher at least knows that his question is "on file," will be answered soon and that he can go on to other things. In most cases, a researcher is more annoyed by wrong answers or the necessity of having to remember to call back at another time (with all the problems of finding the right person or department to answer the question) than he is by the delay.

Without the machine, the student on duty could of course take notes of telephoned messages. This does not always work, for several reasons. At times he is busy attending to patrons at the desk, or he may not understand the question, and it may not be recorded correctly, or, finally, the query may not get to the proper person. By use of the phone service, an experienced librarian, prob- ably a member of the reference staff, can play back each morning the recorded questions with the caller's name and number and either answer the questions himself or see to it that they are directed to the proper person. It is a fact of human nature that inquiries, once having been recorded in such a deliberate, accurate, and "scientific" fashion will receive priority treatment over inquiries received in a less formal manner. It is the difference between asking someone for something in the hallway and asking for the same thing via a signed memorandum.

In summary, such a system has two advantages: (1) it will in actuality provide more service and (2) it will seem to provide more service. It will give the user the feeling that the library is patron oriented, that the librarian did not go home at five o'clock and forget about him and his needs. 